\title{
A Situated Learning Approach to Measuring Financial Literacy Self-Efficacy of Youth
}

DOI:

10.1891/JFCP-18-00038

10.1891/JFCP-18-00038

\section{Document Version}

Accepted author manuscript

Link to publication record in Manchester Research Explorer

\section{Citation for published version (APA):}

Prevett, P., Pampaka, M., Farnsworth, V., Kalambouka, A., \& Shi, X. (2020). A Situated Learning Approach to Measuring Financial Literacy Self-Efficacy of Youth. Journal of Financial Counseling and Planning , 31(2), 229250. https://doi.org/10.1891/JFCP-18-00038, https://doi.org/10.1891/JFCP-18-00038

\section{Published in:}

Journal of Financial Counseling and Planning

\section{Citing this paper}

Please note that where the full-text provided on Manchester Research Explorer is the Author Accepted Manuscript or Proof version this may differ from the final Published version. If citing, it is advised that you check and use the publisher's definitive version.

\section{General rights}

Copyright and moral rights for the publications made accessible in the Research Explorer are retained by the authors and/or other copyright owners and it is a condition of accessing publications that users recognise and abide by the legal requirements associated with these rights.

\section{Takedown policy}

If you believe that this document breaches copyright please refer to the University of Manchester's Takedown Procedures [http://man.ac.uk/04Y6Bo] or contact uml.scholarlycommunications@manchester.ac.uk providing relevant details, so we can investigate your claim.

\section{OPEN ACCESS}




\title{
A Situated Learning Approach to Measuring Financial Literacy Self-Efficacy of Youth
}

\begin{abstract}
In setting a new direction for the field by highlighting the importance of measure development, this paper offers an original approach to modelling financial literacy, in which theories of situated learning meet self-efficacy: an approach that we claim fits well with the aims of program evaluation. It presents results from the validation of a new set of measures, intended for use with 16 to 19-year-olds, of financial literacy self-efficacy pertaining to contexts such as the classroom or the everyday activity of personal banking. Self-efficacy implies a domain in which confidence is measured specific to that context - in this case financial literacy. The data were collected in the United Kingdom from high school and college students enrolled in an optional certificate course in personal financial management. The measures were validated on a subset $(\mathrm{n}=171)$ of a larger sample and was an off-shoot project of a larger three-year evaluation study of the financial literacy certificate course $(\mathrm{n}=2000)$, which provided additional mixed-methods data used in validation. Correlation analysis supports the contention - incorporated within the framework presented - that selfefficacy is context-specific and so measures of self-efficacy must adequately reflect the contexts in which the associated literacies reside.
\end{abstract}

Key words: financial literacy, financial literacy measurement, self-efficacy, situated learning, youth 


\section{A Situated Learning Approach to Measuring Financial Literacy Self-efficacy of Youth}

\section{Introduction}

Despite Lord (2001) identifying it as an " essential requirement for every consumer in the $21^{\text {st }}$ century" (p. 21), in the UK, financial literacy continues to give concern. A major baseline survey of financial literacy in the UK conducted by the Personal Finance Research Centre at the University of Bristol (FSA, 2006) revealed significant clusters of people who do not attend adequately to money management. While some respondents reported making considerable efforts to plan ahead, among almost as many, no or little forward planning was evident, and respondents also clustered around the bottom of the range with regard to choosing financial products and staying informed about financial matters.

Indicative of a renewed international focus aimed at raising levels of financial literacy, the UK's Financial Services Authority (FSA) and the Money Advice Service continue highlighting the pressing need to equip the under twenties with greater financial capability. While this is the age group that faces increasingly complex financial demands within a dynamic digital age. Indeed, long-standing concerns are expressed internationally about the general population's low levels of financial literacy (e.g. FSA, 2006), not least in the context of challenges and advantages that accompany the digitalization of finance and financial technology (See also Dong, 2018; Han, Xiao \& Su, 2019).

This paper proposes a situated-learning (Lave, 1991) informed framework of financial literacy, which also draws loosely on Bandura's (1997) model of self-efficacy, contextualized by Driscoll (2005). We propose an original conceptual framework that identifies four constituent contextual sub-domains corresponding to sites where financial literacy is practiced. These derived from an evaluation study carried out in 2008 (Farnsworth et al., 
2011). We refer to this study as Study 1 throughout, to distinguish it from the study that is the main focus of this paper, and which we refer to as Study 2. The original study evaluated the a national certificate course in financial studies, as it was delivered in English and Welsh high schools and colleges that chose to provide it (usually as an optional accredited 'extra' taught on a weekly basis over the course of a year) for their students - specifically, youths aged 1619, many of whom would go on to university. With no compulsion for them to include it in their curricula, the status of financial education in English and Welsh schools is low. The mathematics curriculum includes topics such as simple and compound interest, but in delivering them, teachers are not required to fully contextualise these topics within real world settings. Consequently, for students who opt to take (where available) a course in financial studies at school or college, this is likely to be their first encounter with personal financial management. It is a minority of students in the UK who take a personal financial management course; especially rare is a long course sustained over the course of one academic year.

Our original evaluation took the form of a three-year longitudinal survey commissioned to examine the influence of financial education provided through the certificate course on students' participation in personal financial management practices. During the study's final year, we identified limitations with single-item analytical analysis (see Shi et al., 2019 for further details) and constructed new measures that offer wider analytical scope and can be applied to future studies. The validation of these highly original measures is a significant focus of this paper. Below, we present the measures, discuss their significance, and detail the process of development, including validation on a subsample of the evaluation study's participants. We first make the case for evaluating youths' financial literacy. 


\section{A Rationale for Evaluating Youths' Financial Literacy}

Politicians and employers have called for educational programs that provide young people with the knowledge, skills and attitudes they need to make informed financial decisions throughout their lives. Although interest in financial education has increased in recent years (e.g. Mielitz, Macdonald and Lurtz, 2018; Xu, 2018), empirical research on its impact has been rather scarce, possibly, as Braunstein \& Welch (2002) suggest, due to the methodological challenges of quantifying the impact of financial education programs. Research in financial literacy has yielded contradictory results - some of which may reflect measurement-instrument-inadequacies. For example, the small number of studies uncovered by a recent systematic review (Amagir, Groot, Maassen van den Brink, \& Wilschut, 2017) found financial education to have minimal effect on children's and adolescents' financial behavior. Moreover, studies using delayed post-intervention tests tend to be inconclusive or indicate small effects. The most positive results were reported in cases where education was provided at 'teachable moments' - moments when education is aligned with an individual's specific and current practical financial needs - or in cases associated with a goal oriented approach (Kalwij et al., 2019; Xiao \& Porto; 2019).

We suggest that one reason for this scarcity of research is that existing measures of financial literacy focus on the measurement of financial knowledge, financial confidence or self-efficacy in 'classroom-situated' financial knowledge, rather than self-efficacy in contexts of financial practices of everyday life. This focus may imply an over-simplistic link, on the part of researchers, between classroom-derived knowledge and its extra-classroom application, and an assumption that such knowledge transfer is unproblematic. Indeed, the literature on theories of teaching and learning highlights the issue of over simplifying knowledge transfer as problematic (e.g. Beach, 1999; Omrod, 2012). The literature on 
theories of learning with respect to knowledge transfer is too vast to summarize here (for a review see Hull \& Schultz, 2001) but, focusing more narrowly on financial knowledge transfer to personal banking, evaluations of the effectiveness of financial education interventions have been inconclusive.

There is a small but growing literature on the development of measures of financial literacy, typically using item response theory and the Rasch model as the tools for validation. Walstad and Rebeck (2017) helpfully detailed the development of the financial literacy academic field, and Knoll and Houts (2012) provided a useful summary of attempts to date to measure financial literacy. They also provided details of the validation of their 20-item instrument, The Financial Knowledge Scale, using item response theory. Their instrument is based on extensive analysis of items used to gauge financial literacy in published research. For all its merits, however, we found the Financial Knowledge Scale insufficiently aligned with our study's foci on the personal financial knowledge and practices of the under 20s, as represented by our participants - whose personal banking practices tended to revolve around the selection of appropriate accounts, saving for short-term goals (e.g. vacations, tech gadgets and equipment, and clothes) rather than bare essentials, and, for those legally old enough, the selection and management of credit cards.

Indeed, for the broad age group that represents what may loosely and variously be called 'children', 'late adolescents', ‘emerging adults' or 'youths', within which our 16 to 19year-old participants fell, we found a paucity of appropriate measurement tools. Nevertheless, we uncovered a small number of studies with this age-focus, including Walstad and Rebeck's (2017) Test of Financial Literacy, which was developed to test high school students' financial knowledge, rather than the application of such knowledge. Similarly, for use with 15- to 16year-olds, is an instrument, strongly contextualized in the German curriculum, detailed by Schuhen and Schürkmann (2014). They pointed out that "further studies about financial 
literacy need to be conducted to construct a valid, theory-based construct in order to achieve transparent and valid results" (p.2). We argue that, as an emerging field, financial literacy learning has yet to develop the kinds of compelling theoretical perspectives that give it scholarly credibility.

\section{Shifting the Focus from the Measurement of Financial Knowledge to include the Measurement of Self-efficacy in Financial Literacy Practice Contexts}

While they have been used for around a decade (as Faulkner (2015) notes in her systematic review), the terms 'financial literacy' and 'financial capability' are still contested and overlapping. For a discussion on this topic, also see Xiao \& O’Neill (2016). There is no consensus on how financial literacy can be conceptually developed, or theorized - nor is there consensus on how to develop or improve people's financial literacy. From his examination of definitions and measurement scales for financial literacy in the academic literature, Kamiya (2017, p.651) observed that ' $[\mathrm{t}]$ he early definition of financial literacy basically meant "financial knowledge," but the latest definition has been extended to include or refer to consumers' financial behaviors, consumers' interactions with their social and economic environments, and the effect of cognitive biases on consumers' financial behaviors'. Yet conceptual clarity and definitional precision are crucial, since they have implications for measurement tools and their development.

Indeed, Kamiya (2017) also made the point that conventional measurement scales for financial literacy have been composed of declarative knowledge questions and numerical ability tests concerning personal finance, reflecting such early definitions. An interesting case, however, is the OECD (2011) measure of financial literacy, which primarily uses items in the knowledge domain - suggesting reliance upon what Kamiya (2017) calls 'an early definition'. Yet the OECD's own definition of financial literacy -“a combination of 
awareness, knowledge, skill, attitude and behaviour necessary to make sound financial decisions and ultimately achieve individual financial wellbeing” (p. 2) - suggests a wide perspective that goes beyond consideration of the knowledge domain.

In relation to the issue of definitional and conceptual clarity, we note a problem with the literature on financial self-efficacy (which has been identified in a range of studies as the best predictor of financial behavior). There has been a recent terminological shift - reflecting growing interest in it - toward the measurement of financial literacy self-efficacy. A search for the phrase "financial self-efficacy" using Scopus identified 25 academic articles, mostly published since 2015, several of which may be traced back - albeit indirectly, in some cases to Prochaska and DiClementes' integrative, biopsychosocial model of change (DiClemente et al., 1991). Lown's (2011) 6-item "Financial Self-Efficacy Scale", for example, is the basis of several of the articles found, and Lown's scale items were, in turn, adapted from Schwarzer and Jerusalem's (1995) General Self-Efficacy Scale, which was based on Prochaska and DiClementes' model. These instruments are intended for use with adults, rather than the youths who were our focus, so their applicability to our study is limited. Yet what is of greater concern to us is these measures' evident anchorage of financial literacy as knowledge, whereas our argument - presented below - is that financial literacy is embedded in social practice(s). Our criticism of the measures referred to above is that they apply the notion of what is presented as general self-efficacy, and general self-efficacy, when operationalized in the form of a questionnaire, looks very similar to general confidence. The self-efficacy scales uncovered in our Scopus search are thus susceptible to some of the criticisms levied at measures of confidence: that they measure decontextualized traits, rather than sociallyembedded practice. Our point is that, without sufficient care - which, in turn, relies upon conceptual clarity and definitional precision - items or questions intended to measure, or presented as measuring, 'self-efficacy' risk, instead, measure confidence. 
The result of such weaknesses is that, as a field, we tend currently to focus narrowly on financial knowledge, often through the lens of confidence - or more recently, general selfefficacy - proxies, rather than more widely on self-efficacy in financial practice. Yet this wider focus is in fact the key concern of policy makers, and indeed of the financial industry. We acknowledge that a major challenge in developing a one-size-fits-all measure of specific financial literacy self-efficacy is that financial practices (behaviors) have deep socio-cultural roots and can vary widely between different social groups and constituencies. Indeed, Davies, Mangan and Telhaj (2005) identified the notion of 'boldness' in explaining gender differences in thinking and attitudes. Cautioning in particular that females tend to underestimate their financial understanding of some issues, they (Davies et al., 2005) highlighted the limitations of research findings that identify clear gender differences in financial knowledge, on the grounds that it may be females' lack of boldness that such findings capture, rather than their financial knowledge.

This variation means that we also need to know about the main contexts within which certain groups practice - applied to our study, these are the contexts within which youths in the UK practice financial literacy. Such consideration was applied to our development of a new measure of financial literacy self-efficacy, which is the central focus of this paper. In the section below we detail the process of developing this measure.

\section{The Financial Literacy Self-Efficacy Framework}

Cutler and Devlin (1996) defined financial literacy as comprising two main dimensions: financial knowledge and financial confidence. In keeping with developments in the field, as we point out above, we use the term 'financial self-efficacy' here, instead of confidence, and advocate its wider adoption for conceptualizing financial literacy. Selfefficacy is the belief we have in our own abilities - specifically, our ability to meet the 
challenges ahead of us and complete a task successfully (Akhtar, 2008). It is related to confidence, but they are not the same thing; as Albert Bandura, observes: "confidence is a nondescript term that refers to strength of belief but does not necessarily specify what the certainty is about... Perceived self-efficacy refers to the belief in one's agentive capabilities, that one can produce given levels of attainment" (Bandura, 1997, p. 382).

General self-efficacy refers to our overall belief in our ability to succeed, but there are many more specific forms of self-efficacy, such as, mathematics (Pampaka, Kleanthus, Hutcheson and Wake, 2011 ) or sports self-efficacy (Singh, Bhardwaj, \& Bhardwaj, 2009). We refer to these more specific forms as self-efficacy domains, and the one upon which we focus in this paper is the financial domain: financial self-efficacy. Since we consider financial literacy self-efficacy as "situated", we recognize that self-efficacy varies depending on context. This variation is supported by Atkinson, McKay, Kemson, and Collard (2006) who found that people could perform well in one domain of financial literacy but less well in another. This finding was accepted by Huston (2010), whose model was the first to include "financial application" as a constituent component of financial literacy, which he defines as "ability and confidence to apply and use knowledge related to personal financial knowledge and products" (p. 307).

Going beyond our identification of a financial literacy self-efficacy domain, we incorporate consideration of contextual variation into our taxonomy, by extending it to include what we call 'contexts of performance-in-practice', which are effectively contextually determined self-efficacy sub-domains (an example of which is financial literacy in the context of personal banking). More precisely, contexts of performance-in-practice are the contexts in which individuals apply their financial literacy; our research (detailed below) revealed four such contexts in which our participants engaged. Though we envisage revising 
and possibly renaming these in the future, we currently label these as contexts of: the classroom; financial performance in contexts (individual); financial performance in contexts (social); and thought performance. By 'thought performance', we mean imagined or envisaged performance. An example that emerged from our data is our participants' contemplation of a career in the financial sector.

One of our aims in sharing this taxonomic conceptualization of self-efficacy domains and contexts of performance-in-practice is to highlight its potential, as an analytical tool, for injecting precision - and, by extension, authenticity - into the focus of research into financial literacy education: to move out from a narrow focus on contrived situations such as classrooms, to a wider view of financial literacy as socially situated. This is the basis of our financial literacy self-efficacy framework, introduced below in Figure 1.

It is important to explain that our framework is developed from Driscoll's (2005, p. 318) 'Adapted Model of Self-Efficacy' (which, in turn, was developed from Bandura's (1997) model of self-efficacy). Neither of these models focused specifically on financial literacy; they are general self-efficacy models, but we identified the potential for Driscoll's model to be adapted for and applied to the context that is our focus. Driscoll's adaptations to Bandura's model contributed what he calls 'inputs' - by which he means the environmental influences on self-efficacy. Our adaptation involved our renaming his four 'inputs, on the bases of contextualizing them in: a) the language of situated learning, made most prominent by the work of Lave and Wenger (1991), and b) the financial literacy self-efficacy domain. We renamed Driscoll's 'performance accomplishments' as 'past experiences'; ‘social persuasion' as 'current context influences'; 'vicarious experience' as 'societal discourses', and 'physiological and emotional states' as 'financial identifications'. By these, we mean, respectively: Individuals' past financial decision-making and past engagement in financial 
social practices and financial discourses; current societal discourses in financial literacy (e.g. advertizing and lifestyle campaigns); current financial literacy influences from a variety of contexts (e.g. family, or peers, or financial literacy education program(s)); and, strength of financial literacy self-identification (e.g. as an "entrepreneur" or as "debt averse", or as being “consumer savvy") (see Farnsworth et al., 2011).

\section{$<$ FIGURE $1>$}

\section{The Importance of Situated Learning}

One of the innovative features of our framework is its focus on the relationship between learning and the social situation in which learning occurs. In contrast to alternative views of learning, this relationship can inform studies of literacy as it implies the negotiation and use of knowledge across everyday life contexts. In this view, learning is situated in certain forms of social co-participation, and is not confined to the acquisition of propositional knowledge.

Social theorists (e.g. Cole, 2005) view learning as a process of change in modes of participation and they typically consider learning as a process of expansive participation in activities across increasing numbers of different contexts. Lave and Wenger (1991) described learning as changing "a set of relations among persons, activity and world, over time and in relation with other tangential and overlapping communities of practice” (p. 98). Literacy becomes not just a mental, but a social, activity; it becomes "a social and cultural achievement - it is about ways of participating in social and cultural groups" (Gee, 1998, p. 10). Change in financial literacy self-efficacy, beliefs about one's ability to perform (participate), to various degrees, in given contexts, then becomes the indicator (proxy) of self-reported learning: a soft, but arguably important, learning outcome. Hence, the 
development of a measure of financial literacy self-efficacy performance-in-contexts-ofpractice opens possibilities for evaluating the impact of financial education programs using change in financial literacy self-efficacy as a proxy measure for learning gain. We wanted to construct and validate a measure of financial literacy self-efficacy that recognizes financial literacy performance in a range of contexts. As mentioned above, our approach was to incorporate a shift to self-efficacy measures pertaining to different contexts-of-use - which, in our study, were key contexts in which financial literacy is performed. In the section below we explain the design and method.

\section{Methods}

\section{The Sample}

The Study 2 participants all took part in Study 1, in which they completed at least two questionnaires and in some cases were also interviewed. This sample of youths was selected from those who responded to our invitation, issued at the end of financial studies classes that we observed as part of Study 1. They were recruited from fifteen different educational institutions, including high schools and pre-university colleges (typically catering for 16- to 19-year-olds, but sometimes older people). [We apply here terms that may be understood in North America and internationally. In fact, the institutions in question were what are known in the UK as $6^{\text {th }}$ forms (within secondary schools), and further education (FE) colleges.] The institutions represented, as a whole, a wide spread of geographical location in the UK (to include England and Wales; the north, south and the midlands) and socio-economic related factors (to include rural, semi-rural, urban, suburban institutions, and some whose students represented diverse cultural groups, while others were primarily White British).

The vast majority of the students in the classes we observed agreed to participate in Study 2 , by completing questionnaires there and then. The resulting sample size is adequate 
for measurement validation (Linacre, 1994), which was the aim of Study 2. We opted to obtain a diverse sample, since our aim was not to generalize the results to the whole population but rather to validate measures for future use with similar groups. Details of the sample are presented in Table 1.

\section{$<$ TABLE 1>}

A focus on the financial literacy self-efficacy of this sample is of interest as they are typically beginning to negotiate personal finance in different contexts and gradually becoming the main decision makers in their lives. This is a constituency whose developmental stage and behavior offer much potential for researching the beginnings of financial identities enacted in practice. Nevertheless, we identity several limitations with our sample.

\section{Data Collection}

Questionnaires were completed in Study 2 toward the end of the year by 171 students, of which a subset of 145 had been part of the broader survey (Study 1 - see Farnsworth et al., 2011). Thirteen of these 145 were also part of our Study 2 interview sample; they represented 7 of the 15 Study 2 institutions. The interviews focused on the youths' educational and career choices and aspirations. Interviewers - all four of whom were highly experienced at this method of data collection - went on to probe how personal financial management related to choices and decision making. Interviews typically lasted twenty minutes and took place in a private room in the educational institution. All interview conversation were fully transcribed and analyzed using NVivo as an aid to thematic analysis.

While the questionnaire responses were the primary source of data applied to our measures validation, they were supplemented by relevant interview data. These supplementary interview data facilitated our interpretation of the person-item difficulty scale 
(see Figure 7). Key demographic data also allowed extensive analysis of measurement invariance, i.e. for establishing the comparability of the measures between relevant subgroups, such as gender groups, and proxy categories of socioeconomic status. The instruments' face validity was assured through piloting with students.

\section{Instrumentation}

For the individual, what personal financial management means and involves varies significantly over the life course and is deeply impacted by sociocultural factors. Financial literacy provides a useful lens through which to observe difficulties, arising from such variation, in constructing general measures. From the relatively extensive literature in the field, we select for reference below only a small selection to illustrate the nuanced (cultural) nature of these social differences to explain why we checked the validity of our constructed measures with respect to income, gender and ethnicity (see the section below on differential item functioning analysis, which checks for validity across different groups of respondents).

Financial cultural practices are associated with, but not defined by, social group; people on low incomes, for example, may make little use of bank accounts for day-to-day money management (Collard, Kempson, \& Dominy, 2003) and have specific attitudes to home credit that are deeply cultural (Brooker \& Whyley, 2005). The research finding, referred to above, that females tend to underestimate their financial understanding (Davies, Mangan \& Telhaj, 2005) elucidates - by exposing potential bases of - findings that indicate clear gender differences in knowledge (e.g. Chen \& Volpe, 1998; Chen \& Volpe, 2002; Hayhore, Leach, Turner, Bruin, \& Lawrence, 2000; Volpe, Chen, \& Pavlicko, 1996). However, the literature is inconclusive in relation to ethnicity-based variation. Chen and Volpe's (2002) study, for example, involved a large sample that included Hispanic people and the authors' multivariate logistic regression results suggested almost no association between race and ethnicity and financial practices. Yet other studies reported ethnic-related 
differences; for example, in their Malaysia-based study, Yong, Yew, and Wee (2018) found differences in the outcomes of financial education between Indian and Chinese participants. Other background characteristics believed to impact financial literacy include education level, work-experience, age, and personal income (Chen \& Volpe, 1998), but we were not in a position to conduct differential item functioning on these additional variables.

Our approach to modelling financial literacy self-efficacy was first to scope the range of financial practices for the target group, using data from the main study (Study 1) to identify a domain of specific financial behaviors or practices favored by the target group.. Comparing savings accounts, dealing with student loan issues, attending appointments at the bank, using savings accounts and the "bank of Mom \& Dad" to budget for lifestyle choices (e.g. vacations and clothes - rather than bare essentials), all represented our sample's typical practices. Our participants usually had a part-time job while remaining in full-time education and living in the family home, and owning a credit card at the age of eighteen, was typically seen as a 'rite of passage' in becoming an economically independent adult.

Our prior knowledge of the Study 1 informed the sub-sample's financial literacy contexts-of- known practice and so informed our questionnaire design. Using the interview data, we developed a series of 4-point Likert type confidence scale items ([1] Not confident at all, [2] Not very confident, [3] Fairly Confident, [4] Very Confident). We scoped the domain of financial capability as mapped out by Atkinson et al. (2006), to include the four areas 'managing money', 'planning ahead', 'choosing products' and 'staying informed' and then crossed these with the contexts of known practice. Informed by the course syllabus and intended learning outcomes, section B of the questionnaire focused on knowledge relevant to the curriculum of the financial studies course, while section A focused on demographic information. Section $\mathrm{C}$ items were derived from the interview data and were intended to scope the target group's social and cultural financial practices. Please contact the authors or 
visit www.teleprism.com/financialliteracyJFCP to access sections B \& C of the questionnaire. The first ten are "doing" items that are situated within the domains of everyday financial activities. The final three items (C14 to C16) are also located in everyday contexts outside of the school classroom. These items were included in the questionnaire even though they are more closely linked with the development of particular financial literacy identities than with financial performance-in-practice (see Figure A2 @ www.teleprism.com/financial literacyJFCP); a few of the items have been very slightly modified following our analysis below). The final recommended instrument is in the Appendix.

\section{Validation within a Measurement Framework}

Our validation process (i.e. the accumulation of evidence to support the validity of the constructed perceived self-efficacy measures) follows a psychometric analysis and was conducted within the Rasch measurement framework; we thus followed the relevant guidelines (Wolfe \& Smith Jr., 2007a, 2007b) which are in accordance with Messick's definitions of validity (Messick, 1989). We extensively employed this approach for the validation of our constructed measures, and have already reported some of these findings elsewhere (e.g. Pampaka, Swain, Jones, Williams, Edwards, \& Wo (2108), Pampaka et al (2013).

The Rasch model was chosen because it allows for instrument validation while providing the means for constructing interval measures from raw data, and in this case can help to construct simple, fit-for-purpose, one-dimensional measures. When data fit the Rasch Model the axiom of additive conjoint measurement is satisfied, a Guttman order of response probabilities - and hence of item and person parameters - is established, items are calibrated and persons measured on a common interval scale. Models of the Rasch family are thus governed by certain assumptions, the most important of which are unidimensionality, local independence, and common item discrimination. In its simplest form (i.e. for dichotomous 
responses) the model proposes a mathematical relationship between a person's ability, the difficulty of the task, and the probability of the person succeeding on that task (Wright, 1999; Wright \& Mok, 2000). The Rasch rating scale model is considered the most appropriate for the scaling problems identified in this paper (i.e. a common Likert type scale). When the response rating scale works, it yields ordinal data that need to be transformed to an interval scale. In Andrich's (1999) terms, the response categories serve to define a continuum, and the ratings can be seen as extensions and refinements to dichotomous responses such as disagree and agree. The model allows the item difficulty of each statement to be based on the way in which an appropriate group of subjects responded to that question in practice, and it establishes the relative difficulty of each item stem in recording the development of an attitude from the lowest to the highest levels recordable (Andrich, 1999; Bond \& Fox, 2001; Wright \& Mok, 2000).

Analysis of the data was performed using the one-parameter Rasch rating scale model (with WINSTEPS software). Our decisions about the validity of the measures are based on consideration of the following statistics:

(i) Item fit statistics that indicate how accurately the data fit the model, and thus provide evidence for fulfillment of the unidimensionality assumption, hence suggesting development of one-dimensional scales;

(ii) Category statistics that indicate the appropriateness of the Likert scale used and its interpretation by respondents, to justify what is usually called communication validity; (iii) Person-item maps and the item difficulty hierarchy which provide evidence for substantive, content and external validity;

(iv) Differential item functioning and person fit statistics which can indicate group differentiation of the constructed measures-- an important aspect of validity when an instrument is used with different groups of persons or on different occasions. Differential 
item functioning is examined in this study for gender and income (via education

maintenance allowance, which was a government social security benefit for students from low income families; this allowance has now been abolished).

\section{Validation Results}

We provide detailed descriptions below of results for the overall analysis, first, to demonstrate the approach for readers unfamiliar with it. We then present the results of the final constructed measures. We refer below to the full process of analysis and interested readers additional figures and tables referred to in the text can be viewed @ www.teleprism.com/financialliteracyJFCP.

\section{Fit Analysis - Unidimensionality}

The overall calibration and the item fit statistics in the Rasch context indicate how accurately the data fit the model and may be used as indicators of potential violations of the unidimensionality assumption. Inconsistent data (e.g. misfit items or persons) may become a source of further inquiry. Fit statistics may also flag items to which responses are overly predictable (overfits), which is an indication that they are in some way dependent on other items and might be the first choices for deletion (Bowles, 2003; Wright, 1994). According to the item fit statistics based on overall analysis with all items (both sections B and C of the questionnaire) (see Table A2 @ www.teleprism.com/financialliteracyJFCP), the most problematic items appeared to be $\mathrm{C} 4$ and $\mathrm{C} 9$, which respectively ask about financial budgeting and about confidence in managing credit cards. Items C12 and C15 were slightly problematic; these respectively sought data on respondents' confidence in discussing financial options with family, and in 'playing' the stock market. Reflections on the items and potential improvements can be viewed @ www.teleprism.com/financialliteracyJFCP). 


\section{Differential item Functioning Analysis}

According to Wright and Masters (1982), when a variable (or measure) is used with different groups of respondents it is essential that the identity of the variable be maintained from one occasion to the next (i.e. from group to group, or from one time point to the next). Only if the item calibrations are invariant from group to group can meaningful comparisons of person measures be made. Our analysis checked for comparability based on gender and whether or not the student held the educational maintenance allowance. Where any group comparisons are intended (a standard practice in survey and other evaluation studies) it is crucial that they are based on unbiased instruments, i.e. with items that are of equal 'difficulty' for equally 'able' subgroups. A statistical way to inform this process is to check for differential item functioning, in order to expose serious threats to the validity of items and tests used to measure an aptitude, ability or proficiency of members of different populations or groups (Thissen, Steinberg, \& Wainer, 1993).

There are different methods or techniques for checking for differential item functioning. The most widely used involve a t-test on estimates of difficulty parameters for the two groups of students: the first method involves a scatter plot of the two sets of item estimates (from each sub-group) with lines indicating the $95 \%$ confidence intervals in item estimates. The points labelled outside the confidence intervals denote the items with high differential item functioning when comparing gender and the disadvantage proxy (education maintenance allowance) student groups. (See Figures A3 and A4 available at www.teleprism.com/financialliteracyJFCP for disadvantage proxy and gender). Another method involves the same information presented as a line graph for the different groups and the averages (and statistically significant differences) are denoted with an asterisk (See Figure A4). 
In relation to the disadvantage proxy, only two items outside the confidence intervals or with a significant difference in the measures between the two groups, with only a small proportion of items marginally in the problematic range. In fact, only "I am confident that I can provide an informed commentary on current issues in the financial industry" (B11) and "In practice I can discuss about financial options with my family" (C12) appeared problematic: C12 was harder for respondents receiving, than for those not receiving, educational maintenance allowance to agree with; B11, which was easier to agree with for those who received the allowance than for those who did not receive it. Similarly, in relation to gender only a few items were potentially problematic with regard to differential item functioning - B13 (financial scam recognition), C15 (stock market) and C12 (discuss financial options with family) - as marginal differential item functioning statistics. B13 and C15 were harder for females to agree with, whereas the opposite is the case with C12 (see Figures A3 \& A5 @ www.teleprismcom/financialliteracyJFCP).

\section{Category Statistics}

Categorization is crucial in designing any ordered-response scale (including the rating scale) and it has two important characteristics: (a) while all categories of a scale should measure a common trait or property, each must also have its own well-defined boundaries, and the elements in a category should all share certain specific exclusive properties, and (b) categories must be in order, and numerical values generated from the categories must reflect the degrees or magnitudes of the trait. Category statistics are given as indicators for this check: the most frequently used indices are the average measure and the threshold (or step calibration). A well-functioning scale should present ordered average measures, with acceptable fit statistics, as was found for this measure (see Figure 6A (@ www.teleprism.com/financialliteracyJFCP). 


\section{The Item-Person Map}

Item-person maps, (such as the one shown in Figure A7 available @ www.teleprism.com/financialliteracyJFCP) present the common logit scale and its distribution of items and respondents.. The higher the item's position (on the right hand side) the harder it is for respondents to agree with it. The item "I am confident that I can provide an informed commentary on current issues in the financial industry" (B11) proved the most difficult for our sample to agree with. On the left of the figure, the higher the position representing him or her, the higher the person scored on this measure, indicating their greater financial literacy self-efficacy.

\section{Dimensionality Diagnostics and Subscales}

Dimensionality diagnostics undertaken (see Figure A8 @ www.teleprism/financialliteracyJFCP) suggested up to 4 sub-dimensions or subscales. This involves checking the results of a principal components analysis of the residuals (with contrasts): when data fit the model residuals should be random and show no structure; observed patterns in the residuals can indicate multidimensionality. An Eigenvalue greater than two, or representing more than $15 \%$ of the unexplained variance, in one of these contrasts, can be considered evidence of multidimensionality, existence of subscales, or possibly a violation of the unidimensionality assumption (Linacre, 2019). In our study, three contrasts exceeded this limit, indicating the possibility of up to four subscales.

We accordingly examined the items, fit statistics, and the contrasts between items suggested by the dimensionality diagnostics, to recalibrate using a step-wise process involving the following main steps: 
1. We observed that $\mathrm{C} 14$ to $\mathrm{C} 16$ fit with the same dimension as B items and that perhaps they measure a dimension of self-efficacy in engaging with the financial industry/sector;

2. This reasoning (in 1. above) was supported by the results of a separate analysis of the B-items, which indicated two sub-dimensions (the main contrasts being between the first and last items);

3. We recognized a 'can'/'could' division of items in B-section;

4. When analyzing items B with C14 to 16 the results clearly suggested a dimension as proposed in 1 and 2 above. B10 to 13 plus C14 to C16 comprise a measure of selfefficacy in engaging with the financial industry. This is an "imagined future" or aspirational, rather than actual, social practice.

Through similar steps as above (1-4), we also examined the data for a further two possible dimensions. The results for both measures (as shown in Table A3 and Figure A9 available $@$ @www.teleprism.com/financialliteracyJFCP) were skewed toward the positive 'more confident' end of the scale. We anticipated the results for the self-efficacy in financial knowledge measure to skew toward the "more confident" end of the scale. We suggest that this skew is indicative of a good measure to capture improvement in knowledge/confidence, since even after an intervention there was no 'ceiling effect'.

In relation to the other subscales indicating self-efficacy in financial performance in "everyday" contexts we analyzed the section C questionnaire items. C9 - which related to confidence in managing a credit card - continued to misfit, suggesting that it should be analyzed as a single item, and so we removed it from further measurement analysis, recalibrating the overall measure without it; its removal did not affect the results in relation to student scores. 
Considering the items in section $\mathrm{C}$ (excluding the 3 already analyzed under the measure of self-efficacy to engage with the financial industry) and inspecting the dimensionality diagnostics and contrasts (as explained above), we uncovered two aspects of financial literacy performance-in-practice self-efficacy, which we label independent activity and social activity. Independent activity is that undertaken alone (e.g. surfing the internet for financial information), while social activity is undertaken with others (e.g. engaging with tellers in the bank). We note, as Atkinson et al. (2006) state, that a person may have high selfefficacy in some aspects of financial literacy and low self-efficacy in others. The two resulting measures - of independent (activity) practice and of social (activity) practice are defined respectively as self-efficacy in financial performance in practice (own) and selfefficacy in financial performance in practice (social) (see Figure A10 for the item-person map and Table A4 for the relevant item fit statistics, available @www.teleprism.com/financialliteracyJFCP).

\section{Using the Measures of Self-efficacy in Further Analysis}

The five measures (one overall and 4 subscales) were added to the larger dataset with other variables and background information. Table 2 presents Pearson Correlations between the four subscales and the overall measure. There were moderate to reasonably high correlations between each of the subscales and the overall financial literacy self-efficacy measure. Notably, the correlation between classroom situated financial literacy self-efficacy and the subscales of financial literacy self-efficacy performance-in-practice contexts was within the moderate to weak band (namely 0.471 and 0.304 ). This band location supports literature (referred to above) that reports a mismatch between financial literacy self-efficacy (largely based on 'knowledge' items) and actual financial literacy performance-in-practice. The correlation coefficients support the view that it is inadequate to use only measures of 
financial knowledge self-efficacy as proxies for financial literacy since the relationships between the subscales are not all strong (see Table 2 below). None of the correlations between the subscales were high enough to suggest omission from the model - all are needed.

$<$ TABLE 2>

The only statistically significant difference between males and females for the overall scale and the individual subscales was self-efficacy to engage with the financial industry $(\mathrm{t}=-3.796, \mathrm{p}=0.000)$, which we anticipated, given the known overrepresentation of males working in the financial services industry. It is more surprising that gender differences were not significant for the overall scale and subscales, but this may reflect the relatively small sample size $(\mathrm{n}=145)$ (see Table 3$)$.

\section{$\langle$ TABLE 3>}

Our framework rests on the premise that specific self-efficacies will be more closely related to the domain in question than general models of self-efficacy would be. We argue that, in the case of financial literacy self-efficacy, a proxy of financial knowledge selfefficacy does not provide the best predictor of financial behavior (self-efficacy is typically considered a better predictor of behavior than is confidence). Our analysis below supports this reasoning since - as predicted by our model in Figure 1 - the self reported behavior data collected in Study 1 correlated most strongly with the associated self-efficacy sub-scale in the most relevant context of financial practice.

\section{$<$ TABLE 4>}

Table 4 indicates that correlations with the output proxies (career likelihood, number of products owned, and test score) varied with the measure, supporting our conceptualization of financial literacy self-efficacy as comprising subscales (described above). The number of products owned correlated most strongly with the overall financial literacy self-efficacy measure ( $r=0.353, p=.000)$, and the highest correlated sub-scale was financial literacy 
performance-in-practice (own) self-efficacy $(r=0.321, p=.001)$. Had only the classroom situated financial efficacy subscale been available (i.e., if only a measure of financial knowledge self-efficacy had been available - what we call the classroom situated subscale) it would have been reasonable to conclude that attainment in financial education has very little impact on personal financial practices (correlation coefficients were all less than 0.26 ). The correlation coefficients presented in Table 4 based on our new subscales warrants greater optimism that financial education can impact financial behavior in everyday contexts. This correlation analysis prompts a rethink - one that reflects a deeply situated perspective on selfefficacy - that challenges the pervasive view that financial education has little impact on financial behavior. This alternative perspective is vital to recognizing the importance of financial education, and to the field's continued development.

The score from the test given to students at the end of the financial course (Study 1) correlated most strongly with the sub-scale measure of classroom situated financial literacy self-efficacy (Study 2), while there was no meaningful correlation between this test score and the self-efficacy subscales (Study 2). This correlation supports our emphasis on a highly situated self-efficacy perspective. It also supports the framework proposed in Figure 1 and highlights the need for precision in defining distinct contexts of practice.

The correlations of the measures of "likelihood of career in financial industry" were strongest for our overall measure. We suggest that the subscales' correlations, referred to above, were similar to each other because various contexts of practice influence career choice; however, notably, as we predicted, the highest correlation was with self-efficacy to engage with the financial sector.

None of the correlations between financial literacy self-efficacy were high; our analysis suggests around $12-15 \%$ of the variance in the output proxies could be accounted for directly by financial literacy self-efficacy. With so very many possible contributory factors, 
and when the output proxies themselves are crude, as they were in our study, we strongly suggest that these degrees of association (correlation) are noteworthy. Ideally, the output variables would pertain to observed, rather than be self-reported, practice, but we had no opportunities for such observation.

\section{Conclusion, Limitations, and Implications}

In this paper we have presented our original model of financial literacy self-efficacy, proposing it as a new framework for evaluating financial education interventions and other evaluations of financial literacy. In so doing, we have drawn upon up-to-date definitions of financial literacy. These definitions have shifted from a focus solely (or almost entirely) on financial knowledge toward one that incorporates the use of such knowledge in other contexts. We have argued that a main implication of such shifts is recognition of the importance of self-efficacy in relation to financial performance in contexts-of-practice as the proxy of choice for financial literacy. In summary, we have shown that, for our dataset, outcome measures correlated most strongly with the most closely associated sub-domain of financial literacy self-efficacy. We have shown that conclusions can depend on which subscale is used, and we have exposed the weaknesses of using only a single proxy of financial knowledge self-efficacy (classroom situated).

Validation of the overall financial literacy self-efficacy measure were presented in detail, and the results of the same procedures with the subscales were summarized (see Appendix). We identified four sub-dimensions of the overall measure:

- $\quad$ self-efficacy in financial knowledge;

- $\quad$ self-efficacy in financial performance-in-practice (own decision-making);

- self-efficacy in financial performance-in-practice in various social contexts; 
- self-efficacy in engagement with the financial industry (an 'imagined futures' aspirational self-efficacy as a kind of thought performance).

This paper thus provides four new measures of financial literacy validated on 16- to 19-yearold youths in Britain. The measures were then used to demonstrate our framework of financial literacy self-efficacy; correlations were (usually) highest between the financial literacy self-efficacy sub-scale and associated outcome proxy for the context of practice.

We argue that research in financial literacy must recognize that there can be, and often is, a disjuncture between knowledge in the context of the classroom and its application in everyday life. The distinction between knowledge acquired in the classroom and its transfer to use in everyday life is crucial. It is a distinction that has been greatly overlooked in the measurement literature about financial literacy. Our validation of both measures of selfefficacy in financial knowledge and self-efficacy in financial performance-in-practice offers a new direction for the field and provides much needed tools for future evaluation studies that may test and contextualize it. Measures of financial literacy self-efficacy in practice should be considered for inclusion in financial education intervention evaluation studies. Since change in literacy self-efficacy can be used as a proxy for learning gain, we propose our measures for adaptation in financial educational program and intervention evaluation.

All of our participants were volunteers, and although their institutions were selected for diversity, the sample was not a strictly representative or random sample. Moreover, since it was recruited from cohorts of self-selecting financial studies (an optional subject) students, the sample is potentially skewed on the basis of predisposition toward and assumed interest in financial education. In addition, analysis of the demographic data revealed the sample to be over representative of low income families compared with the wider population (see Table 1). Since the data were collected at a time of year when their financial studies were nearing completion, the sample may reasonably be considered relatively financially knowledgeable. 
This timing may account for some items' high scores. However, the item score profile suggests that the measures are challenging enough not to have generated a ceiling effect. The sample size was adequate for the purpose of validation of the measures but not large enough to examine interactions of demographics, or for more involved follow-up statistical analyses.

We have already suggested several ways in which our approach may open up possibilities for developing financial educational research. For financial education the implications are a move toward applied learning and competence based assessment. For financial counselors the takeout message is to interpret standardized tests with caution. Until the field has developed sufficiently sensitive tests of financial literacy, there is great value in knowing clients' individual circumstances, wants and aspirations. On the ground qualitative engagement with clients may trump quantitative measures data, if the test is not well connected with the life experiences of clients. For planners we would encourage the search for and use of appropriately context specific measures in their work.

We end by emphasizing the salience for other literacy fields of our highly 'situated' conceptualization of self-efficacy. Such literacy fields include new (digital) literacies, statistical literacy, and mathematics literacy, where there is a known mismatch between performance in the classroom and the application of knowledge acquired in the classroom indeed, whenever there is reason to doubt the straightforwardness of knowledge transfer. Making good measures is a resource intensive process, and placing emphasis on the further development of measures must be ongoing not only in our field of financial literacy, but also more generally in applications of psychology. Yet the development of a measures toolkit that is truly fit for purpose is vital if we are to gain greater precision in research focus. Greater importance must be given to the development of context appropriate measures. 


\section{References}

Akhtar, M. (2008). What is self-efficacy? Bandura's 4 sources of efficacy beliefs. Positive Psychology UK, Retrieved from http://positivepsychology.org.uk/self-efficcaydefinition-bandura-meaning/, 20 November 2018.

Amagir, A., Groot, W., Maassen van den Brink, H., \& Wilschut, A. (2017). A review of financial-literacy education programs for children and adolescents. Citizenship, Social and Economics Education, 17(1), 56-80.

Andrich, D. (1999). Rating scale model. In G. N. Masters \& J. P. Keeves (Eds.), Advances in measurement in educational $R$

research and assessment (pp. 110 - 121). Oxford: Pergamon.

Atkinson, A., McKay, S., Kemson, E., \& Collard, S. (2006). Levels of financial capability in the UK: results of a baseline survey. Consumer research 47. Bristol University.

Bandura, A. (1997). Self-efficacy: The exercise of control. New York: Freeman.

Beach, K. (1999). Chapter 4: Consequential transitions: A sociocultural expedition beyond transfer in education Review of Research in Education (pp. 101-139): American Educational Research Association.

Bond, T., \& Fox, C. M. (2001). Applying the Rasch model: fundamental measurement in the human sciences. Mahwah, NJ: Lawrence Erlbaum.

Bowles, R. (2003). Rejecting best items? Rasch Measurement Transactions, 17(1), 917.

Braunstein, S., \& Welch, C. (2002). Financial literacy: an overview of practice, research, and policy. Federal Reserve Bulletin, 88(11), 445-457.

Brooker, S., \& Whyley, C. (2005). Locked in, kept out: the extent of competition within the UK home credit industry, Joseph Rawntree Foundation [available online at http://www.jrf.org.uk/publications/locked-kept-out-extent-competition-within-ukhome-credit-industry]. 
Chen, H., \& Volpe, R. P. (2002). Gender differences in personal financial literacy among college students. Financial Services Review, 11(3), 289-307.

Cole, M. (2005). Using Cross-Cultural Psychology to design afterschool educational activities in different cultural settings. In W. Friedlmeier, P. Chakkarath, \& B. Schwarz (Eds.), Culture and Human Development: The importance of cross-cultural research for the social sciences (pp. 53-71). New York: Psychology Press.

Collard, S., Kempson, E., \& Dominy, N. (2003). Promoting financial inclusion: An assessment of initiatives using a community select committee approach. Bristol: The Policy Press in association with JRF.

Cutler, N. E., \& Devlin, S. J. (1996). Financial Literacy 2000. Journal of the American Society of CLU \& ChFC, 50(4), 32-37.

Davies, P., Mangan, J., \& Telhaj, S. (2005). Bold, reckless and adaptable? Explaining gender differences in economic thinking and attitudes. British Educational Research Journal, 31(1), 29-48.

DiClemente, C., Proschaska, J. O., Fairhurst, S. K., Velicer, W., Valasquez, M. M., \& Ross, J. S. (1991). The process of smoking cessation: An analysis of the precontemplation, contemplation and preparation stages of change. Journal of Consulting and Clinical Psychology, 59(2), 295-304.

Dong, G. N. (2018). Informal bankruptcy: Health expenditure shocks and financial distress avoidance. Journal of Financial Counseling and Planning, 29(1), 45-59.

Driscoll, M. P. (2005). Psychology of Learning for Instruction (3rd ed.): Pearson.

Farnsworth, V., Davis, P., Kalambouka, A., Ralph, S., Shi, X., \& Farrell, P. (2011). Students' production of curricular knowledge: Perspectives on empowerment in financial capability education. Education, Citizenship and Social Justice, 6(2), 153-167. 
Faulkner, A. E. (2015). A systematic review of financial literacy as a termed concept: More questions than answers. Journal of Business \& Finance Librarianship, 20(1-2), 7-26.

FSA. (2006). (The Financial Services Authority) - Financial capability in the UK: establishing a baseline. London: Financial Capability Team [Retrieved from http://www.fsa.gov.uk/pubs/other/fincap_baseline.pdf, on June 2008].

Gee, J. (1998). The new literacy studies: from "Socially situated" to the work of the social. University of Wisconsin at Madison: Departments of Curriculum and Instruction.

Han, L., Xiao, J. J., \& Su, Z. (2019). Financing knowledge, risk attitude and P2P borrowing in China. International Journal of Consumer Studies, 43(2), 166-177.

Hayhore, C. R., Leach, L. J., Turner, P. R., Bruin, M. J., \& Lawrence, F. C. (2000). Differences in spending habits and credit use of college students. The Journal of Consumer Affairs, 34(1), 113-133.

Hull, G., \& Schultz, K. (2001). Literacy and learning out of school: A review of theory and research. Review of Educational Research, 71(4), 575-611.

Huston, S. J. (2010). Measuring financial literacy. Journal of Consumer Affairs, 44(2), 296316.

Kalwij, A., Alessie, R., Dinkova, M., Schonewille, G., van der Schors, A., \& van der Werf, M. (2019). The effects of financial education on financial literacy and savings behavior: Evidence from a controlled field experiment in Dutch primary schools. Journal of Consumer Affairs,

Kamiya, T. (2017). A review of definitions and measurement scales for financial literacy. Shinrigaku Kenkyu, 87(6), 651-668.

Knoll, M. A. Z., \& Houts, C. R. (2012). The Financial Knowledge Scale: An application of item response theory to the assessment of financial literacy. Journal of Consumer Affairs, 46(3), 381-410. 
Lave, J. (1991). Situating learning in communities of practice. In L. B. Resnick, J. M. Levine, \& S. D. Teasley (Eds.), Perspectives on socially shared cognition (pp. 63-82). Washington, DC, US: American Psychological Association.

Lave, J., \& Wenger, E. (1991). Situated learning: legitimate peripheral participation. Cambridge, UK.: Cambridge University Press.

Linacre, J. M. (1994). Sample size and item calibration stability. Rasch Measurement Transactions, 7(4), 328.

Linacre, J.M. (accessed June 2019), https://www.rasch.org/rmt/rmt201a.htm Lord, L. (2001). From Summing Up - Bridging the Financial Literacy Divide - A CAB Evidence report. NACAB.

Lown, J. M. (2011). 2011 outstanding AFCPE®Conference paper: Development and validation of a financial self-efficacy scale. Journal of Financial Counseling and Planning, 22(2), 54-63.

Messick, S. (1989). Validity. In R. L. Linn (Ed.), Educational Measurement (Third ed., pp. 13-103). USA: American Council of Education and the Oryx Press.

Mielitz, K. K. S., Macdonald, M., \& Lurtz, M. (2018). Financial literacy education in a work release program for an incarcerated sample. Journal of Financial Counseling and Planning, 29(2), 316-327.

OECD INFE. (2011). Measuring Financial Literacy: Core Questionnaire in Measuring Financial Literacy: Questionnaire and Guidance Notes for conducting an Internationally Comparable Survey of Financial literacy. Paris: OECD.

Omrod, J. (2012). Human learning (6th Ed). Boston: Pearson.

Pampaka, M., Kleanthous, I, Hutcheson G.D, \& Wake, G. (2011) Measuring mathematics self-efficacy as a learning outcome, Research in Mathematics Education, 13(2),169190. 
Pampaka, M., Swain, D., Jones, S., Williams, J., Edwards, M. \& Wo, L., (2018) Validating constructs of learners' academic self-efficacy for measuring learning gain, Higher Education Pedagogies. 3, 1, p. 118-144

Pampaka, M., Williams, J., Hutcheson, G., Black, L., Davis, P., Hernandez-Martinez, P., \& Wake, G. (2013). Measuring alternative learning outcomes: dispositions to study in higher education. Journal of applied measurement, 14(2), 197-218.

Schuhen, M., \& Schürkmann, S. (2014). Construct validity of financial literacy. International Review of Economics Education, 16(PA), 1-11. doi:10.1016/j.iree.2014.07.004

Schwarzer, R., \& Jerusalem, M. (1995). Generalized self-efficacy scale. In J. Weinman, S. Wright, \& M. Johnston (Eds.), Measures in health psychology: a user's portfolio. causal and control beliefs (pp. 35-37). Windsor, UK: NFER-NELSON.

Shi, X., Prevett, P., Farnsworth, V., Kwong, K. C., Wan, W., He, F., ... Zhen, L. (2019). Modeling changes to survey response items over time in a british financial literacy education study. Journal of Financial Counseling and Planning , 30(1), 5666.

Singh, T. D., Bhardwaj, G., \& Bhardwaj, V. (2009). Effect of self-efficacy on the performance of athletes. Journal of Exercise Science and Physiotherapy, 5(2), 110114.

Thissen, D., Steinberg, L., \& Wainer, H. (1993). Detection of differential item functioning using the parameters of item response models. In P. W. Holland \& H. Wainer (Eds.), Differential item functioning (pp. 67-114). London Lawrence Erlbaum Associates, Publishers.

Volpe, R. P., Chen, H., \& Pavlicko, J. J. (1996). Personal investment literacy among college students: A survey. Financial Practice and Education, 6(2), 86-94. 
Walstad, W. B., \& Rebeck, K. (2017). The test of financial literacy: Development and measurement characteristics. The Journal of Economic Education, 48(2), 113-122.

Wolfe, E. W., \& Smith Jr., E. V. (2007a). Instrument development tools and activities for measure validation using Rasch Models: Part I - Instrument development tools. Journal of Applied Measurement, 8(1), 97-123.

Wolfe, E. W., \& Smith Jr., E. V. (2007b). Instrument development tools and activities for measure validation using Rasch Models: Part II - Validation activities. Journal of Applied Measurement, 8(2), 204-234.

Wright, B. D. (1994). Data analysis and fit. Rasch Measurement Transactions, 7(4), 324.

Wright, B. D. (1999). Rasch Measurement Models. In G. N. Masters \& J. P. Keeves (Eds.), Advances in measurement in educational research and assessment (pp. 268-281). Oxford: Pergamon.

Wright, B. D., \& Masters, G. N. (1982). Rating scale analysis. Chicago: MESA Press.

Wright, B. D., \& Mok, M. (2000). Rasch Models Overview. Journal of Applied Measurement, 1(1), 83-106.

Xiao, J. \& O'Neill, B (2016), Consumer financial education and financial capability, International Journal of Consumer Studies, 40(6), 712-721.

Xiao, J. J., \& Porto, N. (2019). Financial education and insurance advice seeking. Geneva Papers on Risk and Insurance: Issues and Practice, 44(1), 20-35.

Xu, X. (2018). Assessing a community-based financial literacy program: A case study in California's silicon valley. Journal of Financial Counseling and Planning, 29(1), 142-153.

Yong, C., Yew, S., \& Wee, C. (2018). Financial knowledge, attitude and behaviour of young working adults in Malaysia. Institutions and Economies, 10(4), 21-48. 
Table 1: Basic demographic characteristics of participants

\begin{tabular}{|c|c|c|c|c|}
\hline Gender & Female & 60 & $34 \%$ & \\
\hline & Male & 116 & $66 \%$ & \\
\hline & Total & 176 & & \\
\hline \multirow{4}{*}{$\begin{array}{l}\text { Proxy for socio-economic disadvantage } \\
\text { (educational allowance) }\end{array}$} & Yes & 107 & $61 \%$ & \\
\hline & No & 68 & $39 \%$ & \\
\hline & Missing & 1 & $1 \%$ & \\
\hline & Total & 176 & & \\
\hline \multirow[t]{7}{*}{ Ethnicity } & White British & 66 & $38 \%$ & \\
\hline & Asian Heritage & 72 & $41 \%$ & \\
\hline & Afro Caibbean Heritage & 18 & $10 \%$ & \\
\hline & Chinese Heritage & 3 & $2 \%$ & \\
\hline & Other & 5 & $3 \%$ & \\
\hline & Missing & 2 & $1 \%$ & \\
\hline & Total & 176 & & \\
\hline \multirow[t]{6}{*}{ Age in years } & 16 & 9 & $5 \%$ & \\
\hline & 17 & 82 & $47 \%$ & \\
\hline & 18 & 73 & $41 \%$ & \\
\hline & $19+$ & 10 & $6 \%$ & \\
\hline & Missing & 2 & $1 \%$ & \\
\hline & Total & 176 & & \\
\hline \multirow[t]{3}{*}{ School Type } & High School & 120 & & $68 \%$ \\
\hline & Pre-university College & 56 & & $32 \%$ \\
\hline & Total & 176 & & \\
\hline
\end{tabular}


Table 2: Pearson Correlations between measures

\begin{tabular}{|l|l|l|l|l|}
\hline $\begin{array}{l}\text { Financial } \\
\text { Literacy Self- } \\
\text { efficacy }\end{array}$ & Overall measure & $\begin{array}{l}\text { Classroom } \\
\text { situated }\end{array}$ & $\begin{array}{l}\text { Financial Sector } \\
\text { Engagement }\end{array}$ & $\begin{array}{l}\text { Context (on } \\
\text { own) }\end{array}$ \\
\hline $\begin{array}{l}\text { Classroom } \\
\text { situated }\end{array}$ & $0.790^{* *}$ & & & \\
\hline $\begin{array}{l}\text { Financial Sector } \\
\text { Engagement }\end{array}$ & $0.795^{* *}$ & $0.605^{* *}$ & & \\
\hline Context (on own) & $0.792^{* *}$ & $0.471^{* *}$ & $0.455^{* *}$ & \\
\hline Context (social) & $0.628^{* *}$ & $0.304^{* *}$ & $0.367^{* *}$ & $0.585^{* *}$ \\
\hline
\end{tabular}

$\mathrm{N}=145, * * \mathrm{p}<0.001$

Table 3 - Gender differences and t-tests

\begin{tabular}{|c|c|c|c|c|c|c|c|}
\hline $\begin{array}{l}\text { Financial Literacy } \\
\text { Self-efficacy } \\
\text { measure }\end{array}$ & Gender & $\mathrm{N}$ & Mean & $\begin{array}{c}\text { Std. } \\
\text { Deviation }\end{array}$ & $\begin{array}{c}\text { Std. Error } \\
\text { Mean }\end{array}$ & t-test & Sig \\
\hline \multirow[t]{2}{*}{ Overall } & Female & 48 & 1.1327 & .88215 & .12733 & \multirow[t]{2}{*}{-1.795} & \multirow[t]{2}{*}{0.075} \\
\hline & Male & 97 & 1.4699 & 1.14319 & .11607 & & \\
\hline \multirow[t]{2}{*}{ Classroom situated } & Female & 48 & 1.7352 & 1.34287 & .19383 & \multirow[t]{2}{*}{-1.707} & \multirow{2}{*}{0.09} \\
\hline & Male & 97 & 2.2028 & 1.64541 & .16707 & & \\
\hline \multirow{2}{*}{$\begin{array}{l}\text { Engagement with } \\
\text { the financial sector }\end{array}$} & Female & 48 & .3860 & 1.69116 & .24410 & \multirow[t]{2}{*}{-3.755} & \multirow[t]{2}{*}{$<0.001$} \\
\hline & Male & 97 & 1.5327 & 1.74913 & .17760 & & \\
\hline \multirow{2}{*}{$\begin{array}{l}\text { Performance in } \\
\text { practice - context } \\
\text { (own) }\end{array}$} & Female & 48 & 1.9206 & 1.58454 & .22871 & \multirow[t]{2}{*}{0.777} & \multirow[t]{2}{*}{0.439} \\
\hline & Male & 97 & 1.7121 & 1.48966 & .15125 & & \\
\hline \multirow{2}{*}{$\begin{array}{l}\text { Performance in } \\
\text { practice - context } \\
\text { (social) }\end{array}$} & Female & 48 & 1.8698 & 2.17880 & .31448 & \multirow[t]{2}{*}{0.107} & \multirow[t]{2}{*}{0.915} \\
\hline & Male & 97 & 1.8314 & 1.96541 & .19956 & & \\
\hline
\end{tabular}


Table 4: Correlations of measures with (a) likelihood of a career in the Financial Sector, (b) number of financial products owned and (c) end of unit test scores

\begin{tabular}{|c|c|c|c|c|c|}
\hline $\begin{array}{l}\text { Financial } \\
\text { Literacy Self- } \\
\text { efficacy } \\
\text { measure }\end{array}$ & $\begin{array}{l}\text { Spearman's Rho (unless } \\
\text { other wise stated) }\end{array}$ & $\begin{array}{r}\text { Career } \\
\text { Likelihood }^{(1)}\end{array}$ & $\begin{array}{r}\text { Products } \\
\text { owned }\end{array}$ & $\begin{array}{r}\text { Mark at } \\
\text { course }\end{array}$ & $\begin{array}{r}\text { Mark at } \\
\text { course } \\
\text { (Pearson) }\end{array}$ \\
\hline \multirow{3}{*}{ Overall } & Correlation Coefficient & $-.293^{* *}$ & $.353^{* *}$ & .160 & .145 \\
\hline & Sig. (2-tailed) & .003 & .000 & .057 & .086 \\
\hline & $\mathrm{N}$ & 101 & 100 & 142 & 142 \\
\hline \multirow[t]{3}{*}{ Classroom situated } & Correlation Coefficient & $-.235^{*}$ & $.199^{*}$ & $.259^{* * *}$ & $.252 * *$ \\
\hline & Sig. (2-tailed) & .018 & .047 & .002 & .003 \\
\hline & $\mathrm{N}$ & 101 & 100 & 142 & 142 \\
\hline \multirow{3}{*}{$\begin{array}{l}\text { Engagement with } \\
\text { the financial sector }\end{array}$} & Correlation Coefficient & $-.282^{* *}$ & $.264^{* *}$ & .114 & .093 \\
\hline & Sig. (2-tailed) & .004 & .008 & .176 & .271 \\
\hline & $\mathrm{N}$ & 101 & 100 & 142 & 142 \\
\hline \multirow{3}{*}{$\begin{array}{l}\text { Performance in } \\
\text { practice -context - } \\
\text { (own) }\end{array}$} & Correlation Coefficient & $-.206^{*}$ & $.321^{* *}$ & .061 & .053 \\
\hline & Sig. (2-tailed) & .038 & .001 & .468 & .530 \\
\hline & $\mathrm{N}$ & 101 & 100 & 142 & 142 \\
\hline \multirow{3}{*}{$\begin{array}{l}\text { Performance in } \\
\text { practice-context } \\
\text { (social) } \\
\end{array}$} & Correlation Coefficient & $-.213^{*}$ & $.238^{*}$ & .032 & .045 \\
\hline & Sig. (2-tailed) & .033 & .017 & .709 & .595 \\
\hline & $\mathrm{N}$ & 101 & 100 & 142 & 142 \\
\hline
\end{tabular}




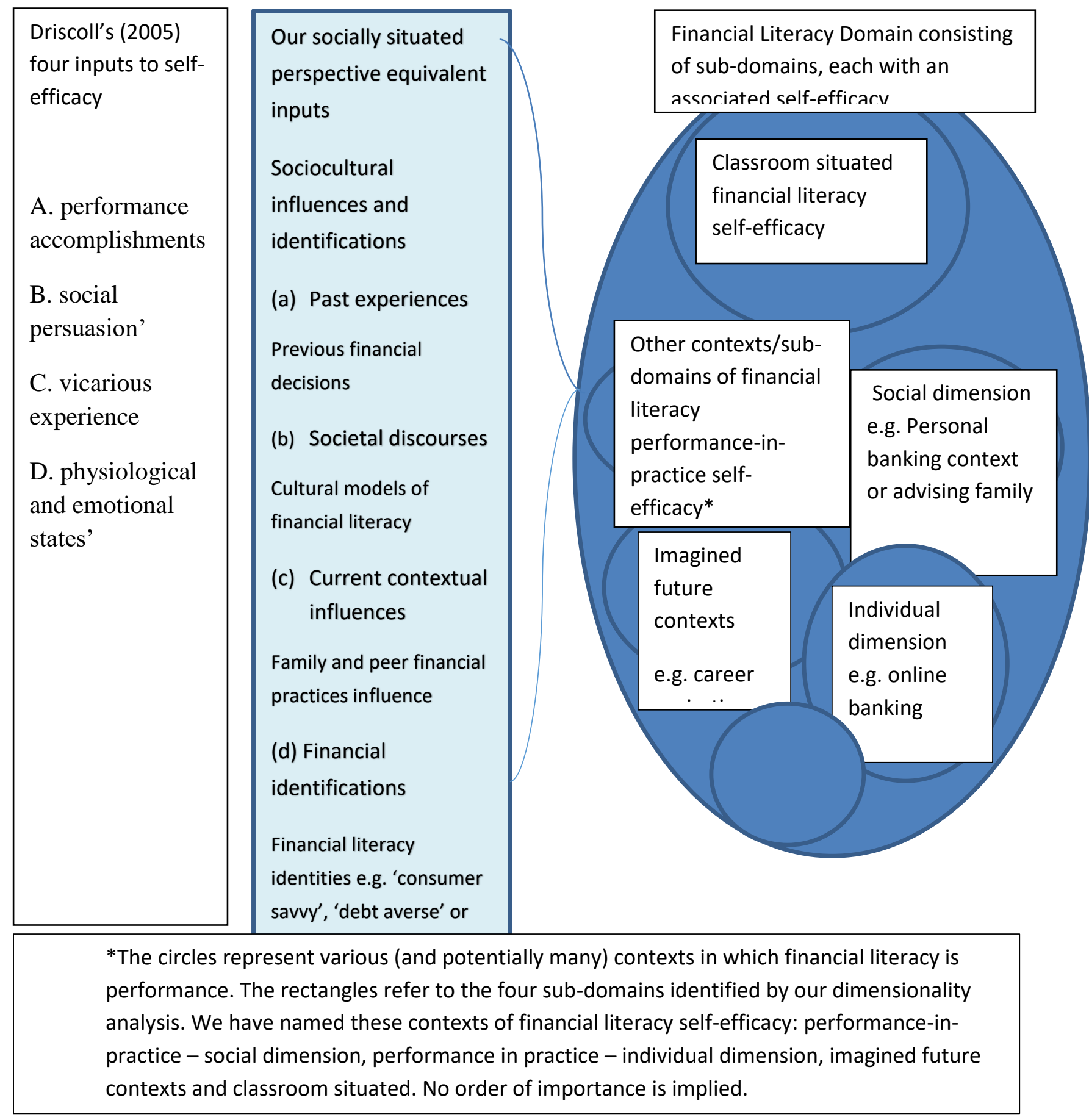

Figure 1: Our framework (model) of Financial Literacy Self-efficacy, taking a highly 'situated' perspective 